\title{
Development of a rapid and confirmatory method to identify ganoderic acids in Ganoderma mushrooms
}

\author{
Ying $\mathrm{Qi}^{1}{ }^{*}$, Lingling Zhao ${ }^{1}$ and Hao H. Sun ${ }^{2}$ \\ ${ }^{1}$ Center for Anti-Aging Research, Shanghai R\&D, Nu Skin Enterprises, Shanghai, China \\ ${ }^{2}$ Center for Anti-Aging Research, Nu Skin Enterprises, Provo, UT, USA
}

Edited by:

Xiao-Ling Zhu, Peking University

Health Science Center, China

Reviewed by:

Shu-Hui Zhang, Shanghai University of Traditional Chinese Medicine, China

Xiao-Ling Zhu, Peking University

Health Science Center, China

${ }^{*}$ Correspondence:

Ying Qi, Center for Anti-Aging

Research, Shanghai R\&D, Nu Skin

Enterprises, No. 116, Building 11,

Lane 572, Bi Bo Road, Shanghai

201203, China.

e-mail: yingqi@cn.nuskin.com;

Hao H. Sun, Center for Anti-Aging

Research, Nu Skin Enterprises, 75

West Center Street, Provo, UT 84601,

USA.

e-mail:hsun@nuskin.com
To examine the composition of lanostanoids in Ganoderma lucidum, we have developed a liquid chromatography-mass spectrometry (LC-MS) method by using the ganoderic acids isolated in our laboratory as reference standards. The identity of 14 peaks in the high performance liquid chromatogram (HPLC) of G. lucidum has been confirmed. By using the HPLC retention times of these ganoderic acids and their mass fragmentation patterns established in this paper, one can use LC-MS to analyze G. lucidum without requiring the reference standards of these 14 ganoderic acids. Subsequently, only the HPLC-UV method would be needed to analyze routine samples of G. lucidum.

Keywords: mushroom, Ganoderma lucidum, lanostanoids, triterpenes, ganoderic acids, LC-MS

\section{INTRODUCTION}

In our ongoing investigations of Traditional Chinese Medicine (TCM) for dietary supplements we are particularly interested in the medicinal mushroom Ganoderma lucidum (W. Curt.:Fr.) Karst because it is a rich producer of lanostanoids. This class of triterpenes has been reported to have distinct pharmacological activities. These include angiotensin-converting-enzyme inhibition, anti-HIV action, antinociceptic action, histamine release inhibition, HMG-CoA reductase inhibition, and liver function stimulation (Mekenna, 1998). The prevalent usage of G. lucidum by cancer patients in Asia also persuaded us to further investigate the active components of G. lucidum. Indeed, we found that the extract of G. lucidum prepared in our labs induced the modulation of secretion from normal human peripheral blood mononuclear leukocytes of cytokines IL-2, IL-4, and IFN- $\gamma$ (Ma et al., 2002).

Solvent partitioning and repeated chromatography, followed by crystallization resulted in the isolation of 32 lanostanoids from the lipophilic extract of the fruiting body of G. lucidum. These include six previously unknown oxygenated lanostanoids: $8 \beta, 9 \alpha$ dihydroganoderic acid J (1), methyl $8 \beta, 9 \alpha$-dihydroganoderate J (2), 20-hydroxylganoderic acid G (3) (Ma et al., 2002), ganoderic acid Sz (4) (Li et al., 2005), 7-oxo-ganoderic acid Z (5), and 15hydroxy-ganoderic acid S (6) (Figure 1). Compounds 5 and 6 both exhibited inhibitory activities against HMG-CoA reductase and acyl CoA-acyltransferase (Li et al., 2006). We have also isolated 26 known lanostanoids, including ganoderic acids I (7) and $\mathrm{C}_{2}$ (8), 12-deacetylganoderic acid $\mathrm{H}(\mathbf{9})$, ganoderic acid $\mathrm{G}(\mathbf{1 0})$, ganoderenic acid $\mathrm{B}(11)$, ganoderic acids $\mathrm{B}(\mathbf{1 2}), \mathrm{AM}_{1}(\mathbf{1 3}), \mathrm{A}(\mathbf{1 4})$, and $\mathrm{H}(\mathbf{1 5})$, ganoderenic acid $\mathrm{D}(\mathbf{1 6})$, ganoderic acids $\mathrm{C}(\mathbf{1 7}), \mathrm{F}$ (18), J (19), DM (20), S and Y, methyl ganoderate I, ganoderiols $\mathrm{B}$ and $\mathrm{F}$, ganoderol $\mathrm{B}$, ganodermic acid $\mathrm{Q}$, ganodermenonol, ganodermanondiol, ganodermanontriol, lucidone A, and lucidenic A (Ma et al., 2002; Li et al., 2005, 2006; and references cited therein). Their structures were determined by using $1 \mathrm{D}$ and 2D NMR and MS spectroscopic methods.

Ganoderma lucidum has usually been taken orally as mushroom powder or in its extract form, whether as prescribed by TCM doctors or in modern pill form. There is a need to understand the composition of the natural material ingested. Liquid chromatographymass spectrometry (LC-MS) has been used wildly to characterize and standardize triterpenes in mushrooms. However, the availability of only limited number of commercial reference standards of lanostanoids has diminished the number of triterpenes to be analyzed (Adamec et al., 2009; Liu et al., 2011). It is not practical to expect every single lab to obtain reference standards by going through laborious and time-consuming steps of isolating and characterizing each individual lanostanoid. The aim of this work is to develop a rapid and conclusive LC-MS method for identification of major triterpenes in Ganoderma mushrooms by using the ganoderic acid samples we isolated.

\section{MATERIALS AND METHODS GENERAL EXPERIMENTAL PROCEDURES}

Melting points were recorded on a Fisher-Johns melting point apparatus. Optical rotations were recorded on a WZZ-1S automatic polarimeter. UV spectra were recorded on a HP-8453 spectrophotometer. IR spectra were recorded on a Nicolet Magna 
FTIR-750 spectrometer. One- and two-dimensional NMR spectra were recorded on a Bruker AMX 400 spectrometer. Acetonitrile used in LC-MS analysis was supplied by Sigma-Aldrich Co. LLC. Other reagents were all supplied by Sinopharm Chemical Reagent Co. Ltd (Shanghai).

\section{FUNGAL MATERIAL}

The mushroom of G. lucidum was identified by Professor Guanyun $\mathrm{Gu}$, School of Pharmacy, Fudan University, Shanghai, People's
Republic of China. A voucher specimen (GL-9807) has been deposited at the Department of Pharmacognosy, Fudan University, Shanghai, People's Republic of China.

\section{IL-2, IL-4, AND IFN- $\gamma$ ASSAYS}

The sample was dissolved in a $0.4 \%$ DMSO solution, then incubated with normal human peripheral blood mononuclear leukocytes in a RPMI 1640 buffer containing 10\% FBS, 50 unit $/ \mathrm{mL}$ penicillin, and $50 \mu \mathrm{g} / \mathrm{mL}$ streptomycin at $37^{\circ} \mathrm{C}$ for $16 \mathrm{~h}$. Levels of

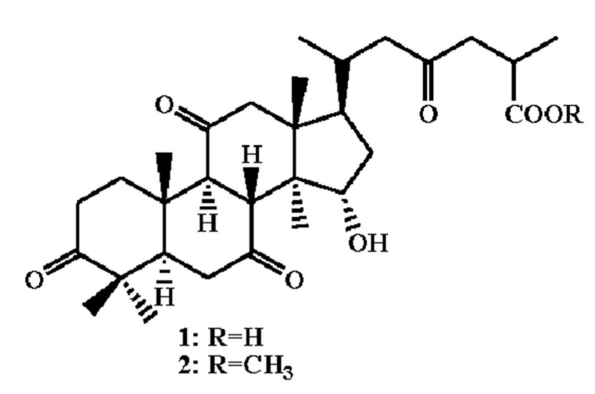

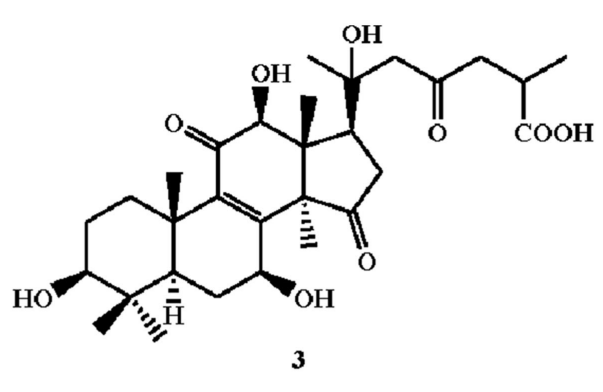

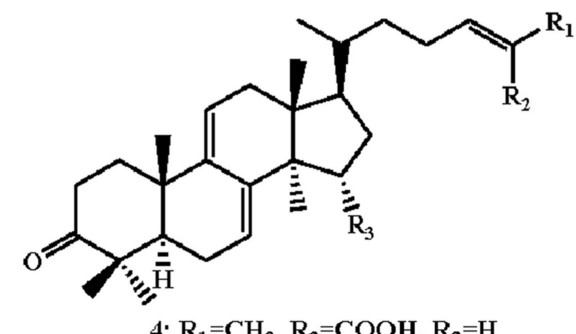

4: $\mathrm{R}_{1}=\mathrm{CH}_{3}, \mathrm{R}_{2}=\mathrm{COOH}, \mathrm{R}_{3}=\mathrm{H}$

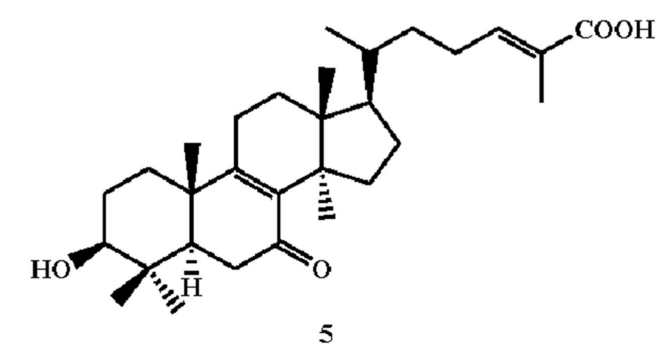

FIGURE 1 | Structures of oxygenated lanostanoids.

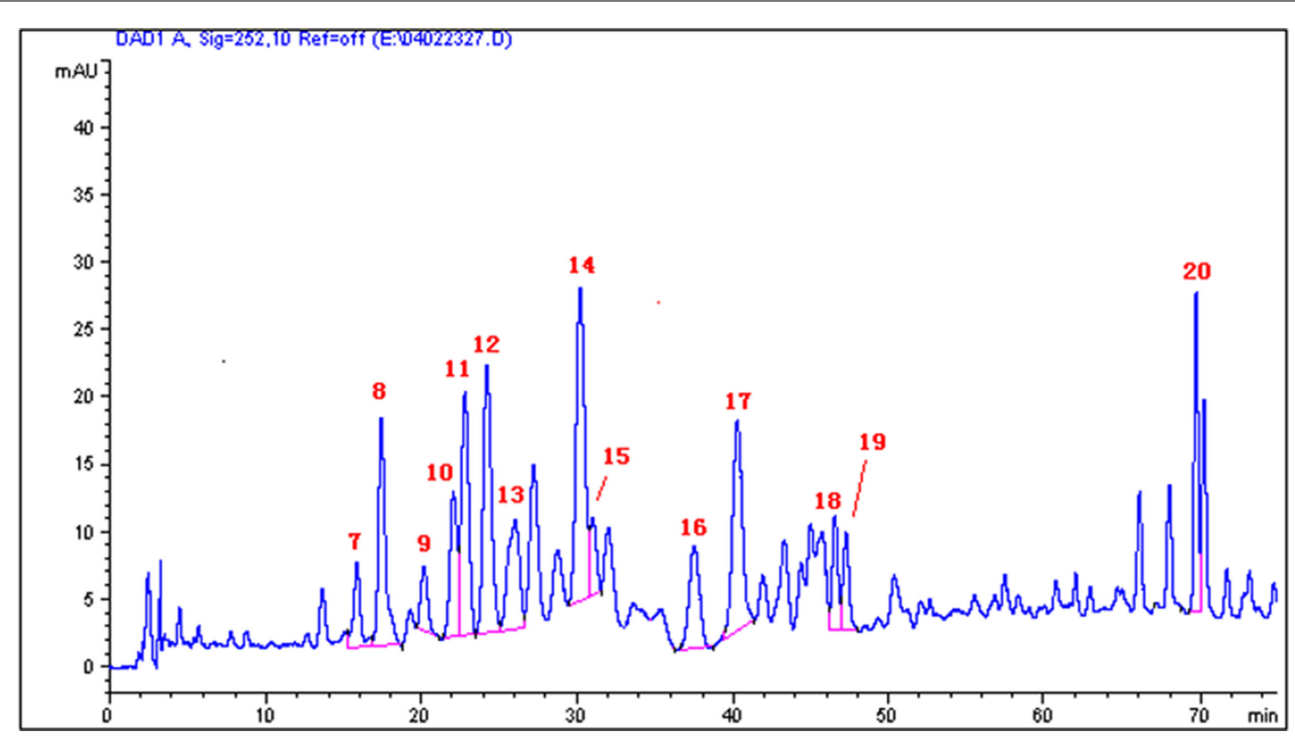

FIGURE 2 | High performance liquid chromatogram of the extract of G. lucidum. 


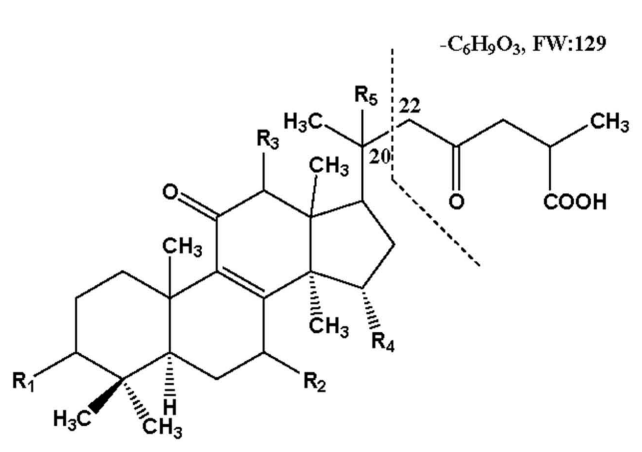

ganoderic acid I (7) $\mathrm{R}_{1}=\mathrm{OH}, \mathrm{R}_{2}=\beta-\mathrm{OH}, \mathrm{R}_{3}=\mathrm{H}, \mathrm{R}_{4}=\mathrm{O}, \mathrm{R}_{5}=\mathrm{OH}$

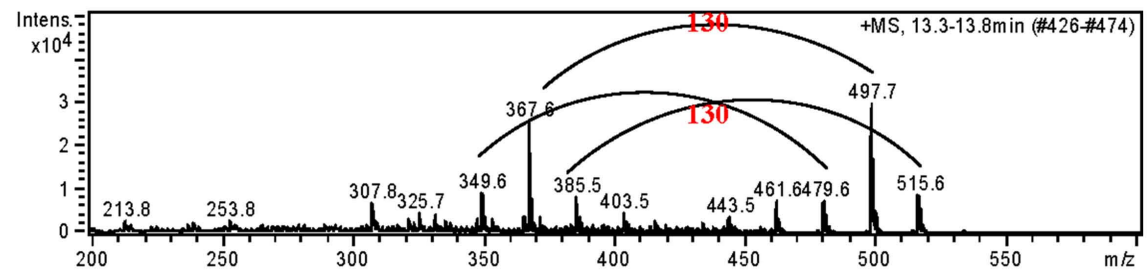

ganoderic acid $\mathrm{C}_{2}(\mathbf{8}) \mathrm{R}_{1}=\mathrm{OH}, \mathrm{R}_{2}=\beta-\mathrm{OH}, \mathrm{R}_{3}=\mathrm{H}, \mathrm{R}_{4}=\mathrm{OH}, \mathrm{R}_{5}=\mathrm{H}$

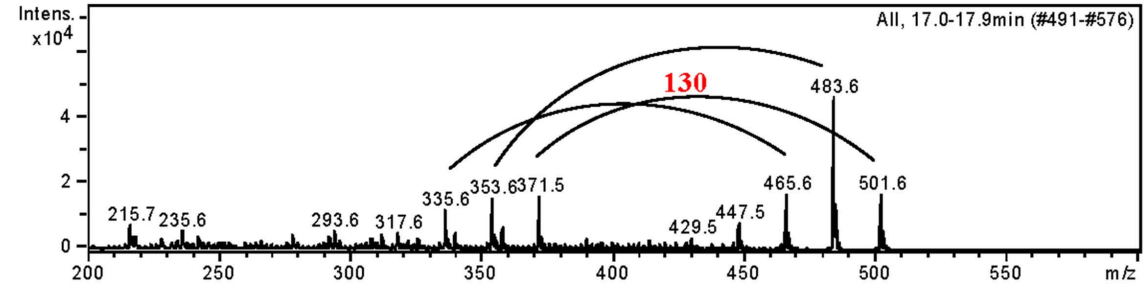

12-deacetylganoderic acid $\mathrm{H}$ (9) $\mathrm{R}_{1}=\mathrm{OH}, \mathrm{R}_{2}=\mathrm{O}, \mathrm{R}_{3}=\mathrm{OH}, \mathrm{R}_{4}=\mathrm{O}, \mathrm{R}_{5}=\mathrm{H}$

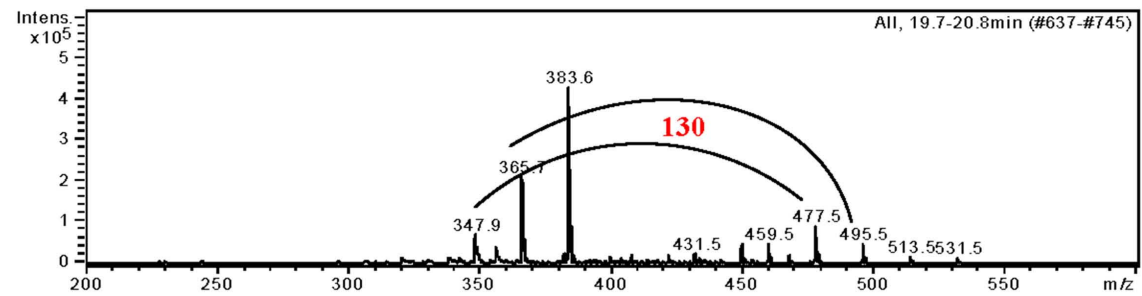

ganoderic acid $\mathrm{G}(\mathbf{1 0}) \mathrm{R}_{1}=\mathrm{OH}, \mathrm{R}_{2}=\beta-\mathrm{OH}, \mathrm{R}_{3}=\mathrm{OH}, \mathrm{R}_{4}=\mathrm{O}, \mathrm{R}_{5}=\mathrm{H}$

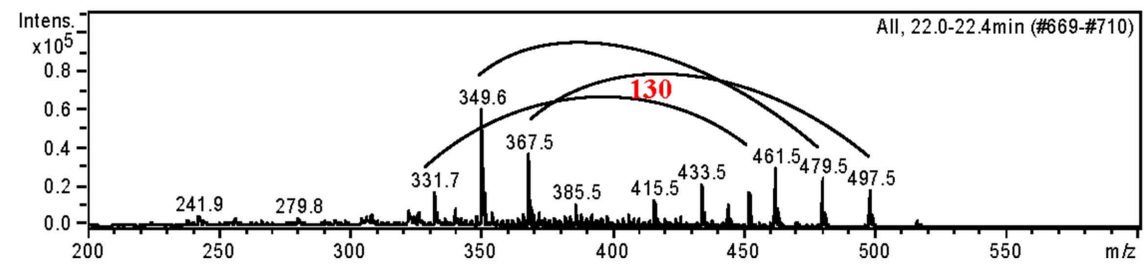

FIGURE 3 | Continued

IL-2, IL-4, and IFN- $\gamma$ were measured using ELISA (Welker et al., 1996; Ma et al., 2002).

\section{HMG-CoA REDUCTASE ASSAY}

A phosphate buffer solution contains $100 \mathrm{mM}$ potassium phosphate (pH 7.5), 8 mM G-6-P, 1 mM NADP, 4 mM EDTA, 2 mM
DTT, and 0.6 U G-6-P-DH was prepared. The compound was dissolved in a $1 \%$ DMSO solution and then pre-incubated with microsomal protein in the phosphate buffer solution at $37^{\circ} \mathrm{C}$ for $15 \mathrm{~min}$. The reaction was started by the addition of $2.5 \mu \mathrm{M}$ $\left[{ }^{14} \mathrm{C}\right] \mathrm{HMG}-\mathrm{CoA}$ reductase and the reaction was run at $37^{\circ} \mathrm{C}$ for $15 \mathrm{~min}$. $\left[{ }^{14} \mathrm{C}\right]$ mevalonate was then quantified. It was determined 
ganoderenic acid $B(\mathbf{1 1}) \mathrm{R}_{1}=\mathrm{H}, \mathrm{R}_{2}=\beta-\mathrm{OH}, \mathrm{R}_{3}=\mathrm{H}, \mathrm{R}_{4}=\mathrm{O}, \Delta^{20,22}$

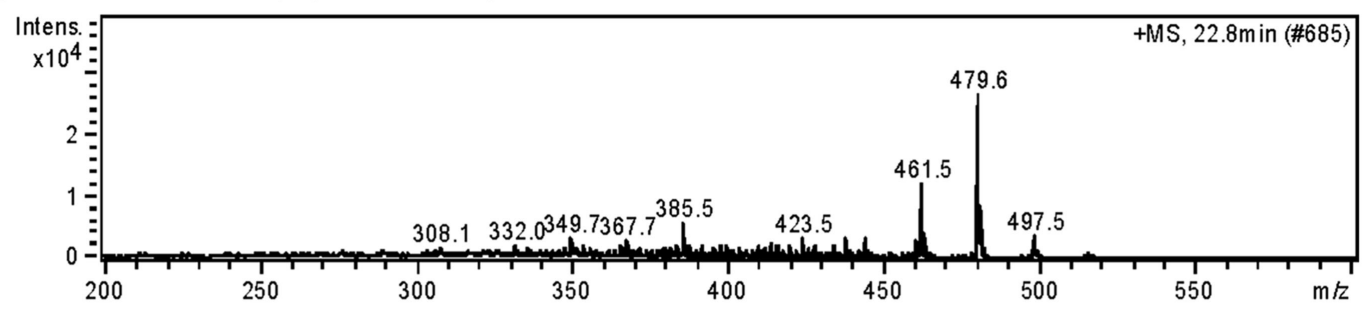

ganoderic acid $B(\mathbf{1 2}) \mathrm{R}_{1}=\mathrm{OH}, \mathrm{R}_{2}=\beta-\mathrm{OH}, \mathrm{R}_{3}=\mathrm{H}, \mathrm{R}_{4}=\mathrm{O}, \mathrm{R}_{5}=\mathrm{H}$

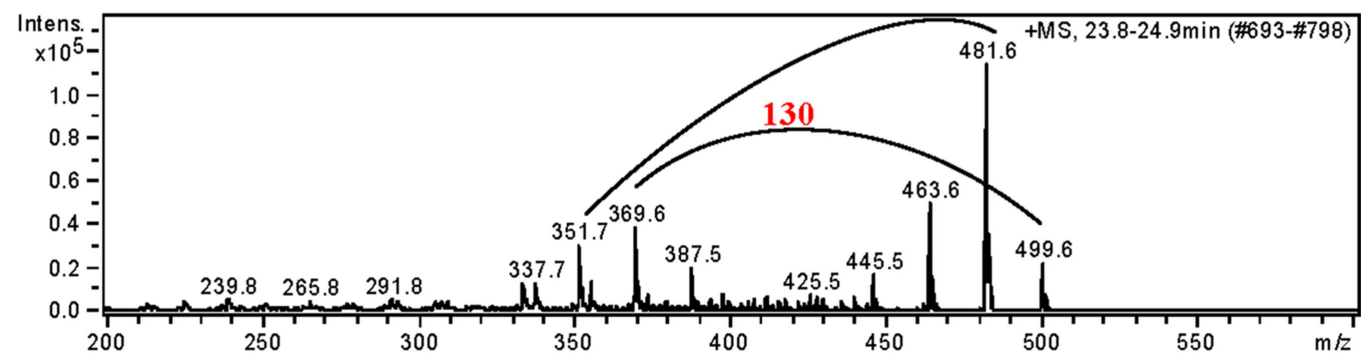

ganoderic acid $\mathrm{AM}_{1}(\mathbf{1 3}) \mathrm{R}_{1}=\mathrm{OH}, \mathrm{R}_{2}=\mathrm{O}, \mathrm{R}_{3}=\mathrm{H}, \mathrm{R}_{4}=\mathrm{O}, \mathrm{R}_{5}=\mathrm{H}$

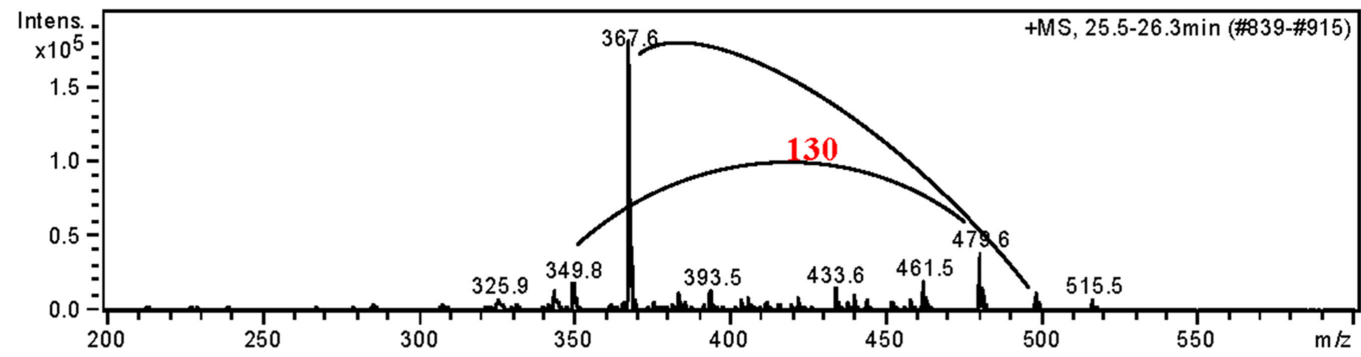

ganoderic acid $\mathrm{A}(\mathbf{1 4}) \mathrm{R}_{1}=\mathrm{O}, \mathrm{R}_{2}=\beta-\mathrm{OH}, \mathrm{R}_{3}=\mathrm{H}, \mathrm{R}_{4}=\mathrm{OH}, \mathrm{R}_{5}=\mathrm{H}$

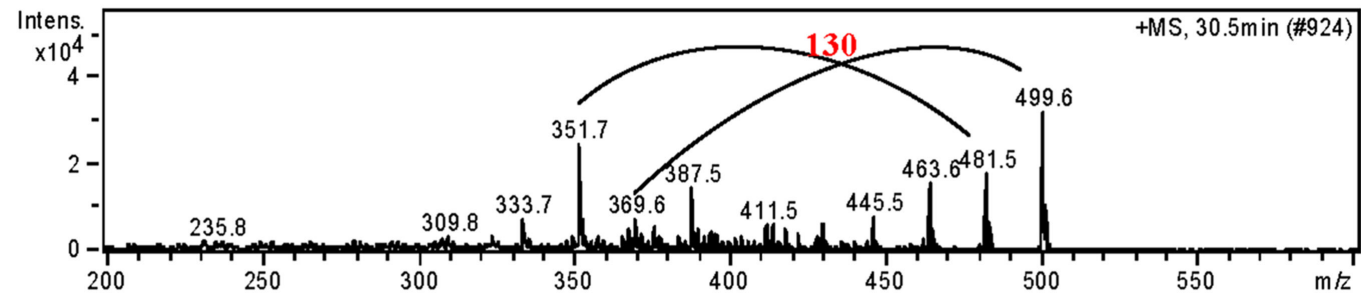

ganoderic acid $\mathrm{H}(\mathbf{1 5}) \mathrm{R}_{1}=\mathrm{OH}, \mathrm{R}_{2}=\mathrm{O}, \mathrm{R}_{3}=\mathrm{OAc}, \mathrm{R}_{4}=\mathrm{O}, \mathrm{R}_{5}=\mathrm{H}$

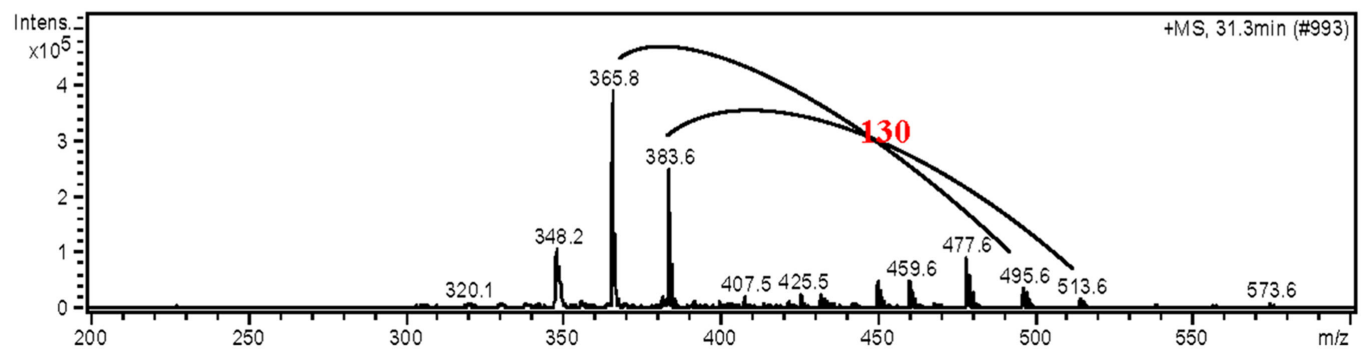

FIGURE 3 | Continued

that compounds $\mathbf{1}$ and $\mathbf{2}$ inhibited HMG-CoA reductase with $\mathrm{IC}_{50}=22.3$ and $21.7 \mu \mathrm{M}$, respectively (Heller and Gould, 1973; Kubo and Strott, 1987; Li et al., 2006).

\section{ACYL COA-CHOLESTEROL ACYLTRANSFERASE ASSAY}

The compound was dissolved in a $1 \%$ DMSO solution and pre-incubated with Wistar rat hepatic microsomes in the 0.2-M 


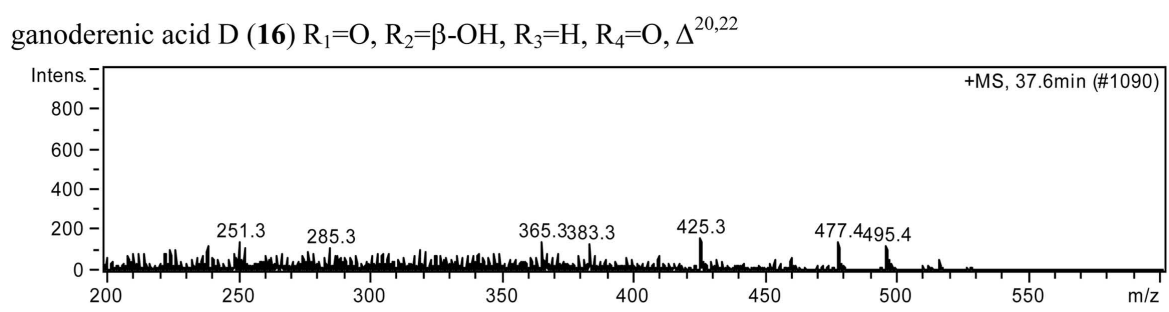

ganoderic acid C (17) $\mathrm{R}_{1}=\mathrm{O}, \mathrm{R}_{2}=\beta-\mathrm{OH}, \mathrm{R}_{3}=\mathrm{H}, \mathrm{R}_{4}=\mathrm{O}, \mathrm{R}_{5}=\mathrm{H}$

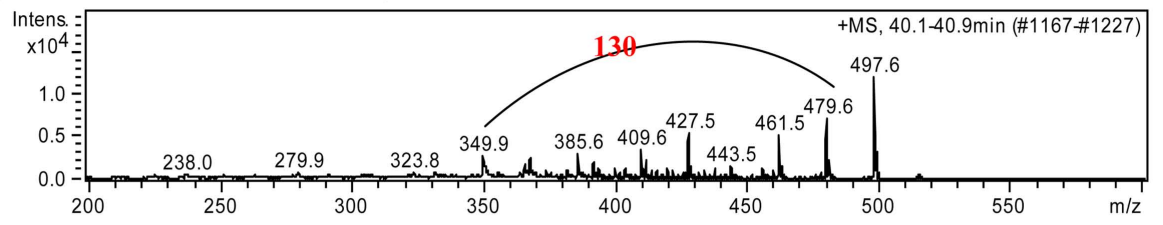

ganoderic acid $\mathrm{F}(\mathbf{1 8}) \mathrm{R}_{1}=\mathrm{O}, \mathrm{R}_{2}=\mathrm{O}, \mathrm{R}_{3}=\mathrm{Ac}, \mathrm{R}_{4}=\mathrm{O}, \mathrm{R}_{5}=\mathrm{H}$

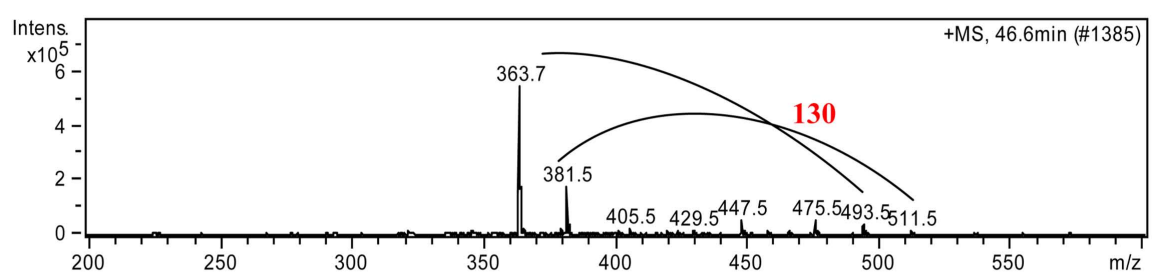

ganoderic acid J (19) $\mathrm{R}_{1}=\mathrm{O}, \mathrm{R}_{2}=\mathrm{O}, \mathrm{R}_{3}=\mathrm{H}, \mathrm{R}_{4}=\mathrm{OH}, \mathrm{R}_{5}=\mathrm{H}$

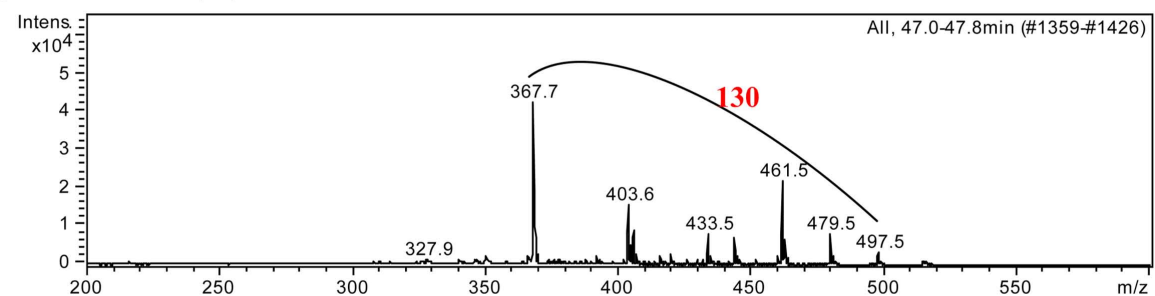

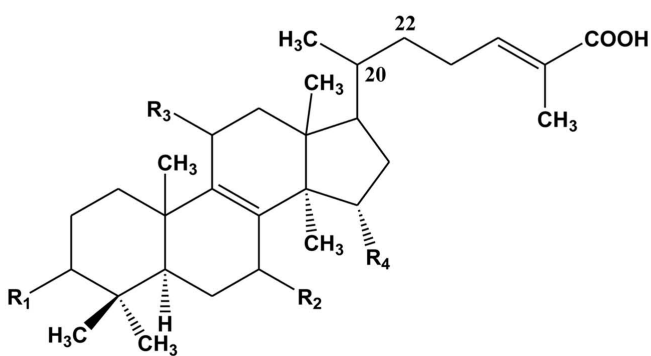

ganoderic acid DM (20) $\mathrm{R}_{1}=\mathrm{O}, \mathrm{R}_{2}=\mathrm{O}, \mathrm{R}_{3}=\mathrm{H}, \mathrm{R}_{4}=\mathrm{H}$

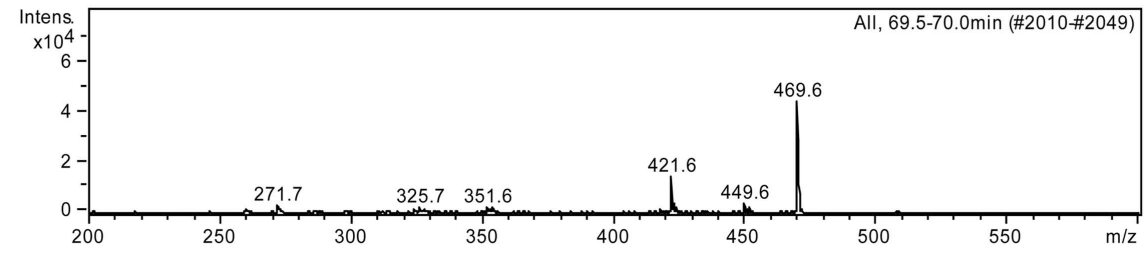

FIGURE 3 | Mass spectra of the major ganoderic acids (7-20) in G. lucidum.

phosphate buffer at $37^{\circ} \mathrm{C}$ for $15 \mathrm{~min}$. The reaction was started by the addition of $18 \mu \mathrm{M}\left[{ }^{14} \mathrm{C}\right]$ palmitoyl CoA-acyltransferase and the reaction was run at $37^{\circ} \mathrm{C}$ for $15 \mathrm{~min}$. $\left[{ }^{14} \mathrm{C}\right]$ cholesterol ester was then quantified. The inhibitory activities, $\mathrm{IC}_{50}$, of compounds 1 and 2 against CoA-acyltransferase were determined to be 5.5 and 47.3 $\mu \mathrm{M}$, respectively (Largis et al., 1989; Li et al., 2006). 


\section{GANODERIC ACIDS}

Ganoderma lucidum mushroom fruiting bodies $(10 \mathrm{~kg})$ were chipped and extracted with $20 \mathrm{~L}$ of $95 \%$ ethanol at $80^{\circ} \mathrm{C}$ three times. After filtering and removing of ethanol, the resulting extract was applied onto a chromatographic silica gel column and eluted with a chloroform/acetone gradient system, followed by a reversed-phase C-18 column chromatographic run with water/methanol. The final purification of the ganoderic acids were accomplished by further high performance liquid chromatogram (HPLC) separation and re-crystallization. Their structure were identified and confirmed by NMR and MS analyses (Ma et al., 2002; Li et al., 2005, 2006). The reference standard solution of each ganoderic acid was prepared by dissolving $1 \mathrm{mg}$ of ganoderic acid in $1 \mathrm{~mL}$ of methanol.

\section{GANODERMA LUCIDUM EXTRACT}

A G. lucidum extract (ReishiMax GLp ${ }^{\mathrm{TM}} 500 \mathrm{mg}$ ) was introduced into $25 \mathrm{~mL}$ of ethyl acetate, sonicated for $30 \mathrm{~min}$, and filtered. The remaining insoluble material was extracted two more times as above. Three filtrates were combined and the solvent was removed under vacuum. The resulting residue was dissolved into $10 \mathrm{~mL}$ of methanol for LC-MS analysis.

\section{LC-MS ANALYSIS}

The HPLC system was controlled by an Agilent MassChrom data system. Chromatographic separation was performed on a Phenomenex luna C-18 column $(5 \mu \mathrm{m}$, $250 \mathrm{~mm} \times 4.6 \mathrm{~mm}$. I.D.) from Phenomenex Co. Ltd. A step gradient solvent system was used: $0 \mathrm{~min} \mathrm{CH}_{3} \mathrm{CN} / 0.1 \%$ aqueous $\mathrm{CH}_{3} \mathrm{COOH} \quad(25 / 75) \rightarrow 35 \mathrm{~min} \quad \mathrm{CH}_{3} \mathrm{CN} / 0.1 \%$ aqueous $\mathrm{CH}_{3} \mathrm{COOH} \quad(35 / 65) \rightarrow 45 \mathrm{~min} \quad \mathrm{CH}_{3} \mathrm{CN} / 0.1 \%$ aqueous $\mathrm{CH}_{3} \mathrm{COOH}(45 / 55) \rightarrow 90$ min $\mathrm{CH}_{3} \mathrm{CN}$ with a constant flow rate at $1.0 \mathrm{~mL} / \mathrm{min}$. Column temperature was set at $30^{\circ} \mathrm{C}$ controlled by a column heater-cooler HP 1100. The elution was measured at the wavelength range of $200-500 \mathrm{~nm}$ by using a photodiode array detector. Agilent triple-quadrupole ion-trap mass spectrometer was equipped with an atmospheric pressure chemical ionization interface (APCI). The mass spectrometer was mass-calibrated with a polyglycol solution. In order to achieve maximum sensitivity the mass spectrometer conditions were set at $450^{\circ} \mathrm{C}$ of APCI temperature, $60 \mathrm{psi}$ of nebulizing gas flow rate, $3500 \mathrm{~V}$ of capillary voltage, and $325^{\circ} \mathrm{C}$ of capillary temperature. Full scam spectra from $\mathrm{m} / \mathrm{z}$ 100 to $\mathrm{m} / z 1000 \mathrm{Da}$ were obtained in the positive ion mode.

\section{RESULTS AND DISCUSSION}

An HPLC method was developed to analyze the lipophilic part of the commercial product ReishiMax GLp ${ }^{\mathrm{TM}}$. Ganoderic acids were separated by a C-18 column with a step gradient solvent system of $\mathrm{CH}_{3} \mathrm{CN} / 0.1 \%$ aqueous $\mathrm{CH}_{3} \mathrm{COOH}$. Figure 2 showed that the chromatogram of the column eluants measured at the wavelength of $252 \mathrm{~nm}$. Subsequent LC-MS analysis with an ion-trap using APCI ionization technique was followed.

The MS spectra of ganoderic acids 7-20 were established by LC-MS. The APCI mass spectra of these compounds exhibited peaks at $m / z\left[\mathrm{M}-\mathrm{nH}_{2} \mathrm{O}+\mathrm{H}\right]^{+}$and $\left[\mathrm{M}-\mathrm{nH}_{2} \mathrm{O}+\mathrm{H}-130\right]^{+}$. The loss of $130 \mathrm{Da}$ in the mass spectra represents the characteristic cleavage of the $\alpha \beta$ bond $(\mathrm{C} 20-\mathrm{C} 22)$ from the $\mathrm{C}=\mathrm{O}$ in the side chain (Figure 3). The absence of these prominent fragments of $\left[\mathrm{M}-\mathrm{nH}_{2} \mathrm{O}+\mathrm{H}-130\right]^{+}$in ganoderenic acids $\mathrm{B}(\mathbf{1 1})$ and $\mathrm{D}(\mathbf{1 6})$, and ganoderic acid DM (20) were expected due to the absence of $\mathrm{C}=\mathrm{O}$ at C23. HPLC retention times $\left(t_{\mathrm{R}}\right)$ of ganoderic acids $\mathbf{7 - 2 0}$, along with their mass fragments, were established and listed in the Table 1.

By comparison of the HPLC retention times and mass spectra of the test sample and reference standards of ganoderic acids (Table 1; Figure 3), the identities of 14 major peaks in the chromatogram of ReishiMax GLP ${ }^{\mathrm{TM}}$ were confirmed. Thus, one can easily use this approach by performing LC-MS analysis on its samples and then comparing with the data in the Table 1 and mass spectra in Figure 3 in this paper to establish the identity of each chromatographic peak. Subsequently, only HPLC will be needed for routine analysis of G. lucidum. This method has been used in our laboratories and extraction factory to examine the quality and quantity of the triterpene composition in incoming mushrooms, crude extracts, finished goods, and competitor products. Our QC

Table 1 | Mass fragments and HPLC retention times of ganoderic acids (7-20).

\begin{tabular}{|c|c|c|c|c|c|}
\hline Compound & $t_{\mathbf{R}}$ & MW & {$[\mathbf{M}+\mathbf{H}]^{+}$} & {$\left[\mathrm{M}-\mathrm{nH}_{2} \mathrm{O}+\mathrm{H}\right]^{+}$} & {$\left[\mathrm{M}-\mathrm{nH}_{2} \mathrm{O}+\mathrm{H}-130\right]^{+}$} \\
\hline 7 & 14.3 & 532 & - & $515(26) 497(100) 479(25)$ & $385(27) 367(85) 349(30)$ \\
\hline 8 & 17.5 & 518 & - & $501(35) 483(100) 465(35)$ & $371(35) 353(31) 335$ (26) \\
\hline 9 & 20.1 & 530 & $531(4)$ & $495(11) 477(22)$ & $383(100) 365(50) 347(18)$ \\
\hline 10 & 22.1 & 532 & - & $497(31) 479(40) 461(50)$ & $367(62) 349(100) 331(29)$ \\
\hline 11 & 22.8 & 514 & $515(2)$ & $479(100) 461(50)$ & - \\
\hline 12 & 24.3 & 516 & - & $499(20) 481(100) 463(45)$ & $369(35) 351(27)$ \\
\hline 13 & 25.8 & 514 & $515(4)$ & $497(7) 479(22)$ & $367(100)$ \\
\hline 14 & 30.4 & 516 & - & $499(100) 481(53) 463(49)$ & $387(47) 351(75)$ \\
\hline 15 & 31.1 & 572 & $573(4)$ & $495(14) 477(35) 459(20)$ & $383(51) 365(100)$ \\
\hline 16 & 37.6 & 512 & - & $495(80) 477(100)$ & - \\
\hline 17 & 40.4 & 514 & $515(4)$ & $497(100) 479(60) 461(45) 427(45)$ & $367(22) 349(22)$ \\
\hline 18 & 46.6 & 570 & - & $511(3) 493(8) 475(9) 447(11)$ & $381(34) 363(100)$ \\
\hline 19 & 47.3 & 514 & $515(2)$ & $497(8) 479(18) 461(50)$ & $403(37) 367(100)$ \\
\hline 20 & 70.2 & 468 & $469(100)$ & - & - \\
\hline
\end{tabular}


lab has used the HPLC chromatograms as sample fingerprints for the cGMP compliant purpose. We believe this method could also be an effective tool for researchers in future studies of other related Ganoderma species.

\section{REFERENCES}

Adamec, J., Jannasch, A., Sudhgaonkar, S., Jedinak, A., Sedlak, M., and Sliva, D. (2009). Development of a new method for improved identification and relative quantification of unknown metabolites in complex samples: determination of a triterpenoid metabolic fingerprint for the in situ characterization of Ganoderma bioactive compounds. J. Sep. Sci. 32, 4052-4058.

Heller, R. A., and Gould, R. G. (1973). Solubilization and partial purification of hepatic 3-hydroxy-3methylglutaryl coenzyme A reductase. Biochem. Biophys. Res. Commun. 50, 859-865.

Kubo, M., and Strott, C. A. (1987). Differential activity of 3-hydroxy3-methylglutaryl coenzyme A reductase in zones of the adrenal cortex. Endocrinology 120, 214-221.
Largis, E. E., Wang, C. H., DeVries, V. G., and Schaffer, S. A. (1989). CL 277,082: a novel inhibitor of ACAT-catalyzed cholesterol esterification and cholesterol absorption. J. Lipid Res. 30, 681-690.

Li, C., Li, Y., and Sun, H. H. (2006). New ganoderic acids, bioactive triterpenoid metabolites from the mushroom Ganoderma lucidum. Nat. Prod. Res. 20, 985-991.

Li, C., Yin, J., Guo, G., Zhang, D., and Sun, H. H. (2005). Ganoderic acid $\mathrm{Sz}$, a new lanostanoid from the mushroom Ganoderma lucidum. Nat. Prod. Res. 19, 461-465.

Liu, Y., Liu, Y., Qiu, F., and Di, X. (2011) Sensitive and selective liquid chromatography-tandem mass spectrometry method for the determination of five ganoderic acids in Ganoderma lucidum and its related species. J. Pharm. Biomed. Anal. 54, 717-721.

\section{ACKNOWLEDGMENTS}

We are grateful to Dr. Jiyuan Ma, Mr. Canjun Li, Ms. Qing Ye, Mr. Jianhua Yin, and Mr. Yanjun Hua for their work in isolation and characterization of ganoderic acids described in this paper.

Ma, J., Ye, Q., Hua, Y., Zhang, D. Cooper, R., Chang, M. N., Chang, J. Y., and Sun, H. H. (2002). Newlanostanoids from the mushroom Ganoderma lucidum. J. Nat. Prod. 65, 72-75.

Mekenna, D. J. (ed.). (1998). Natural Dietary Supplements: A Desktop Reference. St. Croix: Institute for Natural Products Research.

Welker, P., Lippert, U., Nurnberg, W., Kruger-Krasagakes, S., Moller, A., and Czarnetzki, B. (1996). Glucocorticoid-induced modulation of cytokine secretion from normal and leukemic human myelomonocytic cells. Int. Arch. Allergy Immunol. 109, 110-115.

Conflict of Interest Statement: The authors declare that the research was conducted in the absence of any commercial or financial relationships that could be construed as a potential conflict of interest.

Received: 30 November 2011; paper pending published: 25 January 2012; accepted: 16 April 2012; published online: 07 May 2012.

Citation: Qi Y, Zhao $L$ and Sun $\mathrm{HH}$ (2012) Development of a rapid and confirmatory method to identify ganoderic acids in Ganoderma mushrooms. Front. Pharmacol. 3:85. doi: 10.3389/fphar.2012.00085

This article was submitted to Frontiers in tiers in Pharmacology.

Copyright (C) 2012 Qi, Zhao and Sun. This is an open-access article distributed under the terms of the Creative Commons Attribution Non Commercial License, which permits non-commercial use, distribution, and reproduction in other forums, provided the original authors and source are credited. Ethnopharmacology, a specialty of Fron- 